\title{
Coordination Complexes with Lignin-Based Nanoparticles in Targeted Drug Controlled Release and Their Molecular Expression in Cell Lines
}

\author{
Muhammad Ferhan* \\ Lignin Valorization \& Nanomaterials Lab, University of the Punjab, Pakistan
}

Submission: April 23, 2017; Published: May 15, 2017

*Corresponding author: Lignin Valorization \& Nanomaterials Lab, Centre for Applied Molecular Biology (CAMB), University of the Punjab, 87West Canal Bank Road, Thokar Niaz Baig, Lahore-53700, Pakistan, Tel: (+92-42)-3529-3135-36; Fax: (+92-42)-3529-3148;

Email: ferhan.camb@pu.edu.pk/muhammad.ferhan@utoronto.ca

\begin{abstract}
By increasing environmental pollution and fossil fuel depletion has brought an attention for biorenewable and environmentally friendly materials. Among biorenewable polymers, lignin is the second most abundant polymer after cellulose. Lignin nanoparticles can work as bio-carriers for drug delivery by coordinating complex formation with metal ions. A rapid innovation of nanotechnology has elevated the opportunity by using tailored lignin coordinated nanoparticles that interrelate in biological environments for targeting drug delivery. With controlled release in safe existing conditions, the nano encapsulation of dynamic substances has been encouraged of various rational activities mainly because of biopharmaceutical potential of such efforts. The extracellular matrix can activate a series of biological outcomes while nanoparticles interact with cells. The physicochemical characterization of nanoparticles mainly determines the biocompatibility and significance of anticipated results. A connection among nanostructures and their interaction with the biological environment will assist to understand the mechanisms behind these diverse results. The molecular expression, biocompatibility and cytotoxicity can be evaluated by using human cell lines, in actual for nanoparticles used in drug delivery system. Therefore, a suitable safety regulation of nanoparticles on human health within range endpoint is requisite. In this minireview, we will focus on coordinated lignin nanoparticles complex and their molecular expression in cell lines particularly used in drug delivery.
\end{abstract}

Keywords: Lignin nanoparticles; Coordination complex; Biopharmaceutical applications; Biocompatibility; Cytotoxicity; Drug delivery

\section{Significant Statement}

The physicochemical properties of lignin nanoparticles offer an exciting frame for innovative nanomaterials, which can further develop after alterations for targeted controlled release. This minireview summarizes the recent advancement and challenges in effective utilization of coordinated lignin nanoparticles as a carrier for drug delivery within the natural environment for biopharmaceutical applications.

\section{Introduction}

Amid the most recent couple of decades, contrasted with synthetic materials, the utilization of polymer-based materials in various applications has expanded very quickly [1-3]. Agricultural and forestry residues are added up to an invaluable renewable source of lignocellulosic materials. Lignin is the second most abundant biopolymer, comprises up to $30 \%$ of biomass is an enormous misspent source of aromatic compounds. Polymers have make things easier to human lives and influenced each part of cutting edge progress. Today, different sorts of polymers are accessible for domestic to aviation applications and can be effortlessly observed in regular use $[4,5]$.
Nanoparticles can possibly convert for medical diagnosis and therapeutic participations, e.g., diagnostic imaging [68], DNA delivery [9-11], implantable tools, and of particular interests in this review, targeting drug delivery [12]. The notable development of nanoparticles as "controlled release pool" was observed in past, for targeted drug delivery used fighting against many of diseases [13]. There is a basic need to understand the mechanism of interaction between a material and biological system for effective and safe use of nanomaterials for medical applications. Furthermore, it is also important to pay attention specifically on environment as well as the nanoparticle's biocompatibility [14].

The bio responsive materials are susceptible to biological indicators, and interact with therapeutics for the development of next-generation medications. The physiological activators can be classified into three groups: 1: at organ level 2: related to pathological conditions 3: and at cellular specific compartment (Figure 1) [15]. 


\section{Novel Approaches in Drug Designing \& Development}

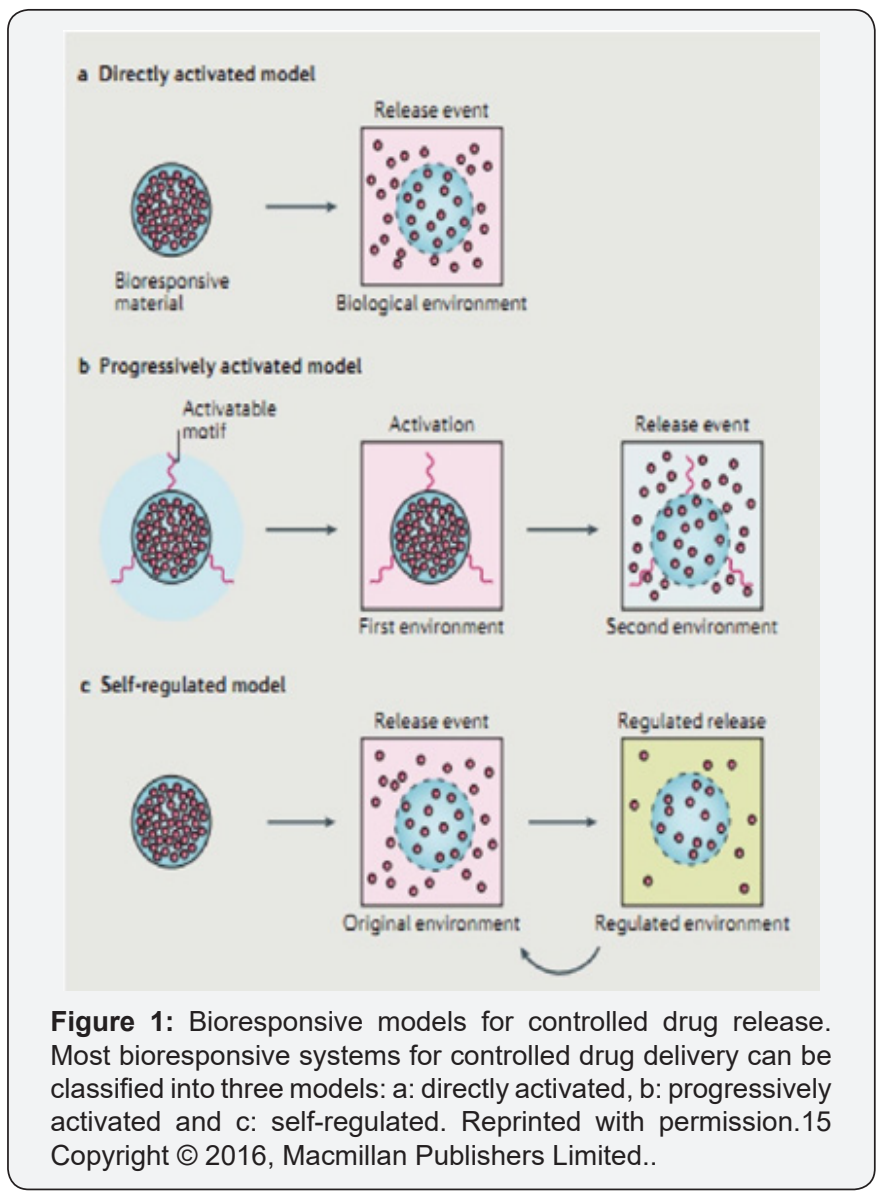

\section{Biological triggers}

The administration method in drug delivery is precisely linked to the medication and therapeutics efficiency [16-19]. The improvement of medical diagnostics stipulate non-invasive or simply persistent advances based on stimuli-responsive materials, which permit for real-time monitoring by expansion of advanced materials to make accuracy in drug release. With the capacity to connect and relate with cells, the emergent appeal for tissue engineering and regenerative medicine directs to vital prerequisites for donated cell organs. Whereas, in the development of medical devices, the assimilation of better execution biocompatible materials is fundamental key for expanding the antibacterial and anti-inflammation means and inhibiting the development of bio films, and fibrosis [20].

Normally, lignin-based functional nanomaterials can be interpreted into practical patterns with biocompatibilities, which can be reinforced into the required expressions, scaffolds or tools in an organized manner with suitable fictionalization mode. Hence, the designing of lignin-based bio functional nanomaterials, mainly for drug delivery and tissue engineering, with the aim of prudence confronts that presently delay clinical version [15].

Lignin is one of the most abundant biopolymers in nature, and a perfect precursor for the development of environmentally friendly nanomaterials, compared to other nanoparticles used for the anticancer therapy [21]. Moreover, in vitro cytotoxicity, hemotoxicity, and anti-proliferation effect were monitored using different carcinoma cell lines [21]. In this minireview, an overview of the mechanisms depicts the destiny of creating and tailoring lignin-based bio functional nanomaterials with a focus on causal motif validation. Subsequently, we focus on the future trend towards improving the state-of-the-art that applies these values.

The materials which are sensitive to $\mathrm{pH}$ are capable to make different physical and chemical changes for instance dissociation, shrinking, degradation, membrane disruption and diffusion, shrinking and swelling [22-24]. Degradation of acidcleavage bonds and protonation of ionizable groups can be affected by due to $\mathrm{pH}$ sensitivity [25]. Concerning $\mathrm{pH}$ alterations, the coordination complexes have potential to accumulate and release drug through cleavage and arrangement of coordination bonds. By using several types of carriers, containing mesoporous hybrid monoliths, mesoporous metal oxides, mesoporous silica nanoparticles, and coordination polymer nanoparticles, has been attained during different $\mathrm{pH}$-receptive systems.

The coordination binding strengths in both host-carrier and coordination-polymer systems are dependent on the pH-responsive system [26]. The drug released in endosomal and lysosomal sections, upon $\mathrm{H}^{+}$-stimulus which expose to intracellular organelles of cancer cells and eventually start killing tumor [27]. Under selected $\mathrm{pH}$ conditions, a significant release of drug molecules exhibited severe cytotoxicity against HeLa cells than coordination polymer nanoparticles (CPNs) [28].

An ideal $\mathrm{pH}$ gradient for intracellular delivery, required for acidification of endosomes and their subsequent fusion with lysosomes. At cancerous cells the local acidification commonly found or inflammatory sites have also been often used for disease-specific controlled drug delivery. The typical examples are the polymerized polymers from maleic anhydride, $\mathrm{N}, \mathrm{N}$-dimethylaminoethyl methacrylate, acrylic acid, and methacrylic acid $[29,30]$. The proton pump inhibitors and some proteins, prevention from gastric degradation is crucial for acid degradable drugs. Carboxyl containing groups have a higher solubility at basic $\mathrm{pH}$ and thus could be used for protecting acidsusceptible drugs for intestine targeted delivery [31].

The gold standard for estimation of new polymers planed for delivery of nucleic acids, although its effectiveness and protection has been exceeded by other contenders compared to poly-ethylenimine approved by FDA [32]. At present, the degradation of $\mathrm{Ca}_{3} \mathrm{PO}_{4}$ within acidic solid tumors free confined $\mathrm{Mn}^{2+}$, developed $\mathrm{pH}$-achievable contrast agent, which then bound to proteins for increased reflexivity during magnetic resonance imaging (MRI) [33]. For instance, the nanocarriers recognizes with $\mathrm{pH}$ - reactive pattern gone through charge conversion in somewhat acidic tumor environment which direct to up regulate endocytosis in the cancerous cells. For improved cancer diagnostics, the charge transferring tactic has also been employed for in vivo cancer imaging [34]. 
Xing $L$ et al. [35] proposed a simple pH-responsive release system by combining a metal ion and ligand or selfaccumulating these groups with biodegradable host molecules to form nanoparticles with "metal-ligand" or "host-metal-ligand" constructs. Natural systems (e.g., transferrin recycling in cells), is turning into a strong contender for a latest stimulus-responsive route which is inherent to $\mathrm{pH}$-responsive activities of metalorganic coordination bonding. Coordination bonds ("metalligand" or the "host-metal"), instigate significant damage to the nanoparticles and consequent release of ligand molecules under assigned $\mathrm{pH}$ conditions [35].

The productive release of anticancer drugs invigorate coordination binding groups at $\mathrm{pH}$ 5.0-6.5, by selecting suitable metal ions, and employing amino group functionalized mesoporous silica. In addition, a vector bearing $\mathrm{pH}$-responsive binding functional groups is created to facilitate in drug release devoid of substantial binding capacities [36]. A mesostructure integrated with surfactant/silica hybrid in coordination bonding system could be effective for $\mathrm{pH}$-responsive drug delivery functions. As result of self-assemble biocompatible F127 Pluronic nonionic surfactant and silica source has been designed a meso structure via liquid-crystal templating route, in which F127 act as host molecules. In addition, metal ions such as $\mathrm{Zn}, \mathrm{Cu}$, and $\mathrm{Fe}$ and drugs have been established whilst into the mesostructure synthesis, to develop F127-metal-drug coordination-bonding pattern [37].

A pH-responsive system by engineering a coordination bond-based " $\mathrm{NH}_{2}$-metal-Doxorubicin (DOX)" arrangement in the mesopores has been explored by Zheng $\mathrm{H}$ et al. [38]. The intensity of coordination bonds on both segments have been constructed from the parts of $\mathrm{NH}_{2}$ loading amount, metal ion, and the counteranion associates with metal ion. Under physiological condition, the pH-responsive delivery system was static whereas it was erratic with the DOX release activated by the minor decline to $\mathrm{pH}$ 6.0-5.0. The effective cellular consumption of this pH-responsive system for cancerous cells has been verified by cell assay. It provides a new vision into the molecular mechanisms which standardize the stimulus of chemical bonds in the restrain region. Consequently, it redirects new potential of permeable materials for advanced applications in adsorption and desorption of biological and paramedical materials for antitumor therapy [38].

The pH-tunable inorganic materials have newly come forward as substitutes for drug delivery applications however organic materials are mainly used. In addition, acid-degradable materials for instance $\mathrm{Ca}_{3} \mathrm{PO}_{4}$ and liquid metal might be interesting owing to their biodegradability and the non-toxic or low-toxicity metabolism products $[39,40]$. The metallic cores (composed of gallium-indium alloy) of the nano-formulation were able of combination and degradation by attack of protons during liquid-metal-based drug-delivery system [40].
Degradation of calcium phosphate within acidic solid tumors free restricted $\mathrm{Mn}^{2+}$, just developed an actively $\mathrm{pH}$ - contrasting agent, which then bound to proteins for improved relativity during MRI [33]. At present, the scientists get benefited of pHsensitive supramolecular gels that were established in acidic environments but soluble at neutral $\mathrm{pH}$ values to build gastricresident devices. An intestinal elastomer was created with poly (acryloyl 6-aminocaproic acid) (PA6ACA) and poly (methacrylic acid-co-ethyl acrylate) [41].

The pH-sensitive hydrogels have been exploited for construction of smart drug-delivery systems for regenerative medicine [42]. For example, dimethyl-aminoethyl methacrylatebased scaffolds were used to produce a pro-healing outcome for tissue regeneration adept of unstable oxygen and nutrient transfer by rising in an acidic environment [43].

The redox potential is present in both tissue and cellular level. In animal cells, the disulfide couple present in glutathione/ glutathione has been established as the most copious redox couple where glutathione is creates at a level that is two to three orders of degree higher in the cytosol than in the extracellular fluid [44].

A higher glutathione concentration in tumour tissues in contrast to normal tissues have exposed in a rodent model [45]. The reactive oxygen species (ROS) at reducing state are also linked with pathological conditions including cancer, arteriosclerosis, stroke, and tissue injury. In presence of reducing agents the disulfides transform to thiols, including glutathione and the resulting thiol groups can reversibly modify disulfide bonds on oxidation [46]. At mild reaction conditions of thiol-disulfide replace and construct to disulfide-containing materials. Disulfides encored in material system in the form of disulfide cross linkers $[47,48]$.

ROS such as hydrogen peroxide $\left(\mathrm{H}_{2} \mathrm{O}_{2}\right)$ and hydroxyl radicals mainly targeted Oxidation-responsive materials. Sulfur-based is a major class of oxidation-responsive materials. An Oxidation exchangeable poly propylene sulfide (PPS) with poly ethylene glycol (PEG), researchers are trying to develop amphiphiles which enable of self-assertion [49]. Moreover, a thioketalcontaining material has been attained for efficient gene delivery [50].

Ferrocene-containing materials have been examined because of redox-sensitivity initiated with Ferrocene [51]. A wide range of diseases, covering from cardiovascular diseases to druginduced organ failure, has the potential to enhance the diagnosis and treatment by screening located ROS levels. Developing enzyme-free ROS sensors symbolizes an attractive approach by integrating ROS-reactive materials. A thin layer of hydro-gel polymer having ROS-degradable thiocarbamate linkages was able to sensing drug-induced liver injury by noting the oxidative pressure in the blood [52]. 


\section{Novel Approaches in Drug Designing \& Development}

However, Lu has thoroughly reviewed a summary of design rationale emphasizing on several guidelines with an importance on expediting the latent conversion of bioresponsive materials (Figure 2) [15]. The structural or mechanistic complexity is frequently confined by conversion of bioresponsive materials. Biomedical applications of bioresponsive materials should be based on homogeneity, rather than garnishing complicated structures and integrating with new methodology [15].

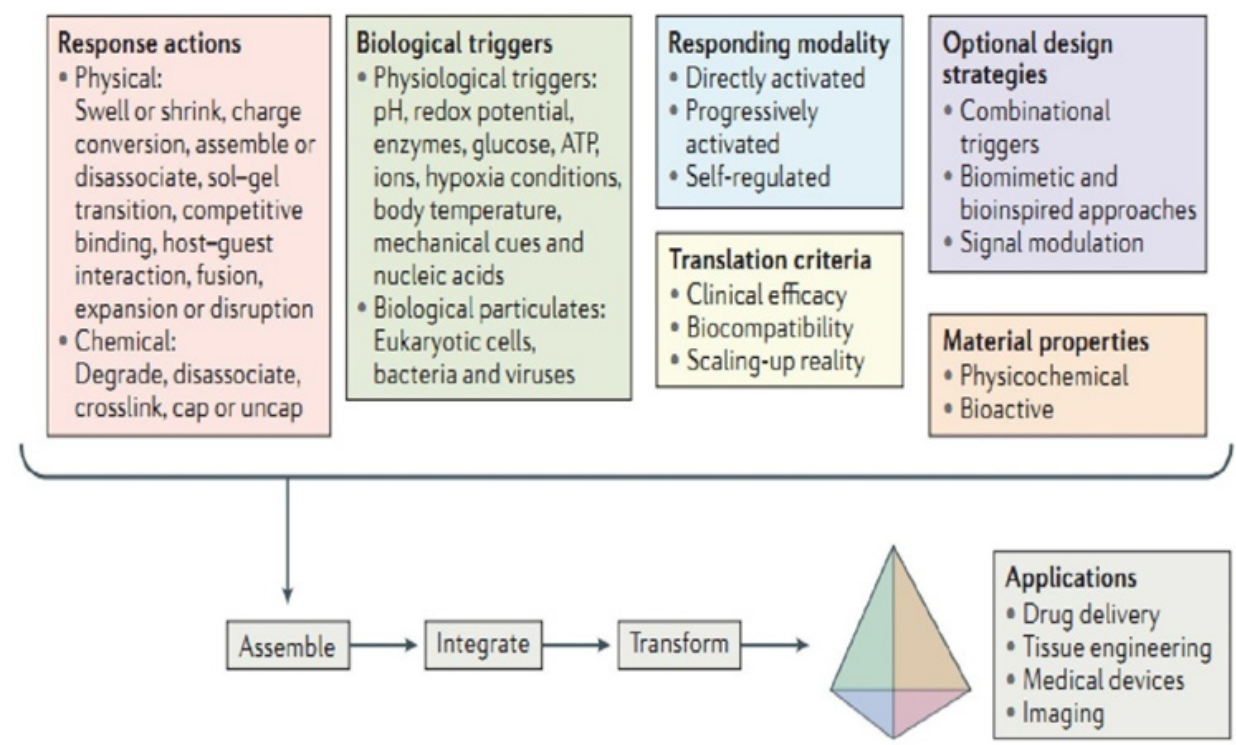

Figure 2: Different views incorporating the reacting mode, physiological activators, response elements, material resources, design process and translational bioinformatics, serve as 'building blocks' for engineering bioresponsive materials for several applications. Reprinted with permission.15 Copyright $\odot$ 2016, Macmillan Publishers Limited..

\section{Nanoparticles for drug delivery}

Nanoparticles can be used for drug delivery and their size particles are in submicron varying from 100-1000nm. As Buzea et al. [53] defined nanoparticles "particles as minimum one dimension smaller than $1 \mu \mathrm{m}$ and likely as small as atomic and molecular length scales $(\sim 0.2 \mathrm{~nm})$." The other organizations defined nanoparticles as "the particles which should have a size less than $100 \mathrm{~nm}$ in at least one orthogonal direction." In field of nanotechnology, it is not easy to chase extensions due to emerging nature of this field appeal a similar range of scopes regarding each scientific domain.

For drug delivery, nanosized particles have enormous assurance for their viability as pharmaceutical carriers and can be prepared using a wide range of materials for instance polymers, lipids, viruses, and organo metalic compounds; thus, their use in medicine is expected to extend fast for future [54]. As for chemotherapy drugs, the nanoparticle drug complexes have ability to alleviate toxicity and side effects linked with raw pharmaceuticals [54,55]. In addition, for targeted drug release and enhanced solubility could be possible via numerous methods for example enfolding, micellization, and structural design of enclosed protein [56].

The specific localization and reduced toxicity of therapeutic drugs is supportive, while, the nanocarriers by itself may cause toxicological risk to patients rather than that of toxic chemicals [54]. Over the past decade, some of contrary toxicological reactions detected, including lung inflammation, aggregation of platelets in blood, and malfunction of mitochondria in cells [54].

The toxicological effects may alter with nanoparticle composition due to material composition contain metal and inorganic particles e.g., silver, gold, platinum, and metal oxide [57], solid-lipid nanoparticles, nano emulsions, polymer-based materials such as PLGA, and lipid-based particles such as nano liposomes. The biological responses can be triggered by make some modifications in physicochemical properties such as surface exchange, hydrophobicity, solubility, size, shape, and aggregation propensities [58]. A major area of study in nano medicine biocompatibility will be explored by manipulation of these physicochemical properties [59].

\section{Coordination complex of lignin nanoparticles}

The lignin polyphenols can be used as the organic matrix which further coordinates with the inorganic cross linkers such as iron, silver, gold, palladium and platinum. Due to its multi functionality, the lignin can be further exploited into the development of coordinated complexes with metal ions. The previous study shown that kraft lignin can be easily used to synthesize microcapsules with non toxic side effects [60]. In view of the development of new materials, the researchers are trying to explore the different parameters which affecting the release and stability of lignin nanoparticles by stacking and/or complex formation.

Due to presence of significant amount of phenolic hydroxyl groups, assist to synthesis of stable and versatile coordinate complexes with metallic ions like Fe (III) reported by Bartzoka 
et al. [61] The development of reactive materials, owing to the active site of the supramolecular structural design with metal and organic particles; they hold conjugated physiochemical properties of metallic ions and the organic matrix which allow for the development of controlled structures and functionalities by modifying the different building blocks [62,63]. An active substance integrate into nano encapsulation within a coating material and has increased massive attention now, since it offers a cost-effective way to enclose and deliver several actives, including drugs, cells, pesticides and flavors in the cavity formed within the shell walls and the internal phase by attaining a controlled release rate of the components [64]. As a result of their odd properties and applications better to their mass complements, nanostructures of natural polymers have entertained gradually developing interest [65]. Furthermore, evading the use of environmentally effecting organic solvents; their preparation methods contain easy handling in aqueous medium. The ability to create such tiny structures is vital to a great deal of modern science and technology $[66,67]$. Therefore, the development of engineering tactics for nanoparticles and nano capsules are at the basis for progress in materials design.

\section{Metallic nanoparticles}

Metallic nanoparticles have ability for use in both diagnostic imaging and targeted drug delivery. Aim to increase the therapeutic sign of anticancer drugs during passive or active targeting; these nanoparticles are frequently dispensed in solid colloidal system and alleviating toxic effects by preventive drug tolerance to healthy cells and tissues [68]. To transfer large drug amounts also increase its circulatory half-life because of metalbased particles potential. Surface modification is probably owing to significant surface area-to-volume ratio.

In 1920s, for treatment of tuberculosis, colloidal gold nanoparticles were used [57]. Since then, colloidal gold nano suspension has been extensively investigated as drug and gene delivery tools [54]. They can be produced in diversity forms (e.g. rod, dot) [54] and are simply visible within micromolar $(\mu \mathrm{M})$ concentrations, affirming their use in imaging applications [57].

Cells have been exposed regarding to biocompatibility to intake gold nanoparticles without any cytotoxicity [54,57]. A median lethal dose (LD50) of above $5 \mathrm{~g} / \mathrm{kg}$ of body weight using nano gold suspension with a particle diameter of $50 \mathrm{~nm}$ explained by Lai et al. [69] Colloidal gold nano suspension, remain to be effectively explored for the function of drug delivery and other applications. Research in this field is supposed to expand over the next few decades [68].

\section{Established guidelines}

Drug release methods, no matter how appealing they look, have no power except they are reasoned sufficiently biocompatible was earlier referred. Lacking authorization from a regulatory agency such as the FDA or the European Medicines Agency (EMEA), is repeatedly role of one another. To address the specific properties to nanomaterials, could it be immune system or surface chemistry modifications are needed to accessible instructions tricky run the use of nano medicine (Figure 3).

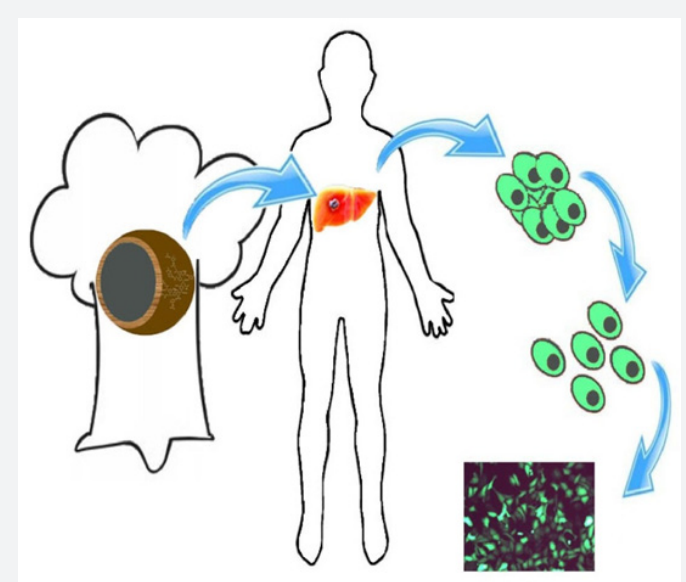

Figure 3: Encapsulated lignin nanoparticles (LNPs) targeted to human cell-lines and their morphological characterizations.

The need for nanotechnology-particular regulatory principles is prepared even more transparent, as novel applications of nanotechnology in medicine and appeal for sanction remain to flow from globally research institutes. Apart from, regulated laws have yet to be successful. Overall, continued in vitro and in vivo testing is required to construct a catalog of data on the matter of nanoparticle biocompatibility. Moreover, after ample scientific facts, will regulatory agencies put onward in-depth struggle of emergent new guidelines [70].

\section{Conclusion and perspectives}

This review is proposing to give an outline of latest verdicts of coordination complex of lignin nanoparticles. For many years, scientists have been trying to exploit efficient and biocompatible drug delivery systems based on nanoparticles as carrier. The rising significance of biocompatible drug delivery system in linked to human health is still far from our final goal. Experimental outcomes should follow the analytical procedures that consider finally the effect caused by exposure to drug delivered. To develop new techniques, biocompatibility is becoming a major barrier because of uncertainty over the mechanisms of drug delivery.

Based on the findings to date, the impact of materials sensitive to endogenous stimuli undergo from incoherent target biological parameters along with patients. Biological signals may be significantly unlike between animal models and humans. Thus, the specified information linked with the targeted signals must be cautiously saved and estimated.

However, the nanoparticles applications are still imperfect by their anonymous biocompatibility which may instigate their sudden elimination through the immune systems. Certainly, the deeper insight of mechanistic studies about physicochemical properties of nanoparticles will be effective which refer to further explain their specific interaction with the immune system. The nanoparticles can be fast assembled because of their 
immense piling tendency of lignin, as well as, metal chelating with phenolic groups at alkaline $\mathrm{pH}$. Metal-lignin nanoparticles (M-LNPs) coordinated complex may enhance expression of protein, controlled release and stability compared to lignin nanoparticles (LNPs).

The particles may be used to create stable complexes with transition metals such as gold $(\mathrm{Au})$. The lignin-Au nanostructures will be of interest in a wide range of applications including computed tomography (CT) imaging, photo thermal therapy and radiation therapy. The hydrophobic lignin-NPs will be coated with the hydrophilic polymer poly (ethylene glycol) (PEG) to prevent particle-particle aggregation and ensure stability in the biological milieu. The lignin-NPs are also well suited as drug delivery vehicles for hydrophobic small molecule chemotherapeutic agents such as paclitaxel and doxorubicin.

Therefore, the lignin-NPs need to be explored for delivery of Au and hydrophobic drugs. These findings will help guide the design and development of lignin-based nanoparticles (ligninNPs) for complexation of inert metals and encapsulation of hydrophobic small molecules. The lignin-Au nanostructures will have unique physicochemical characteristics and improved transport properties unachievable using AuNPs alone, creating promise for future applications in radiotherapy of cancer. Conclusively, the physicochemical characterizations and radio sensitization of this tailored system will motivate us to produce new novel materials and their applications in targeted release.

\section{Acknowledgment}

The author thanks to their potential institute (CAMB, PU, Lahore) and particularly to Higher Education Commission (HEC), Pakistan Grant No: 21- (1105/SRGP/R\&D/HEC/2016) for providing the necessary facilities and funds to accomplish this work.

\section{References}

1. Zhang C, Subramanian H, Grailer JJ, Tiwari A, Pilla S, et al. (2009) Fabrication of biodegradable poly(trimethylene carbonate) networks for potential tissue engineering scaffold applications. Polym Adv Technol 20(9): 742-747.

2. Pilla S, Gong S, O'Neill E, Yang L, Rowell RM (2009) Polylactide-recycled wood fiber composites. J Appl Polym Sci 111(1): 37-47.

3. Pilla S, Kramschuster A, Yang L, Lee J, Gong S, et al. (2009) Microcellular injection-molding of polylactide with chain-extender. Mater Sci Eng C 29(4): 1258-1265.

4. Chalivendra VB, Shukla A, Bose A, Parameswaran V (2003) Processing and mechanical characterization of lightweight polyurethane composites. J Mater Sci 38(8): 1631-1643.

5. Gao C, Yu L, Liu H, Chen L (2012) Development of self-reinforced polymer composites. Prog Polym Sci 37(6): 767-780.

6. Padmavathy B, Vinoth Kumar R, Jaffar Ali BM (2012) A direct detection of Escherichia coli genomic DNA using gold nanoprobes. J Nanobiotechnol 10: 8.

7. Hua D, Yi Xu, Yanhua L, Zhijung C, Huilin G, et al. (2012) Gold Nanoparticles with Asymmetric Polymerase Chain Reaction for Colorimetric Detection of DNA Sequence. Anal Chem 84(3): 12531258.
8. Guerrero S, Herance R, Rojas S, Mena J, Gispert J, et al. (2012) Synthesis and In Vivo Evaluation of the Biodistribution of $\mathrm{a}^{18} \mathrm{~F}$-Labeled Conjugate Gold-Nanoparticle-Peptide with Potential Biomedical Application. Bioconjug Chem 23(3): 399-408.

9. Law M, Jafari M, Chen P (2008) Physicochemical characterization of siRNA-peptide complexes. Biotechnol Prog 24(4): 957-963.

10. Jafari M, Chen P (2009) Peptide mediated siRNA delivery. Curr Top Med Chem 9(12): 1088-1097.

11. Jafari M, Soltani M, Naahidi S, Karunaratne N, Chen P (2012) Nonviral approach for targeted nucleic acid delivery. Curr Med Chem 19(2): 197-208.

12. Fischer HC, Chan WC (2007) Nanotoxicity: the growing need for in vivo study. Curr Opin Biotechnol 18(6): 565-571.

13. Goldberg M, Langer R, Jia X (2007) Nanostructured materials for applications in drug delivery and tissue engineering. J Biomater Sci Polym Ed 18(3): 241-268.

14. Williams DF (2008) On the mechanisms of biocompatibility. Biomaterials 29(20): 2941-2953.

15. Lu Y, Aimetti AA, Langer R, Gu Z (2016) Bioresponsive materials. Nat Rev Mats 1: 16075.

16. Tibbitt MW, Dahlman JE, Langer R (2016) Emerging Frontiers in Drug Delivery. J Am Chem Soc 138(3): 704-717.

17. Kost J, Langer R (2012) Responsive polymeric delivery systems. Adv Drug Deliv Rev 64: 327-341.

18. Mitragotri S, Burke PA, Langer R (2014) Overcoming the challenges in administering Biopharmaceuticals: formulation and delivery strategies. Nat Rev Drug Discov 13: 655-672.

19. Wang S, Huang P, Chen X (2016) Hierarchical Targeting Strategy for Enhanced Tumor Tissue Accumulation/Retention and Cellular Internalization. Adv Mater 28(34): 7340-7364.

20. Vegas AJ, Veiseh O, Gürtler M, Millman JR, Pagliuca FW, et al. (2016) Corrigendum: Long-term glycemic control using polymer-encapsulated human stem cell-derived beta cells in immune-competent mice. Nat Med 22(4): 446.

21. Richter AP, Bharti B, Armstrong HB, Brown JS, Dayne Plemmons, et al. (2016) Synthesis and Characterization of Biodegradable Lignin Nanoparticles with Tunable Surface Properties. Langmuir 32(25): 6468-6477.

22. Mura S, Nicolas J, Couvreur P (2013) Stimuli-responsive nanocarriers for drug delivery. Nat Mater 12(11): 991-1003.

23. Lu Y, Sun W, Gu Z (2014) Stimuli-responsive nanomaterials for therapeutic protein delivery. J Control Release 194: 1-19.

24. Apostolovic B, Danial M, Klok HA (2010) Coiled coils: attractive protein folding motifs for the fabrication of self-assembled, responsive and bioactive materials. Chem Soc Rev 39(9): 3541-3575.

25. Hoffman AS (2013) Stimuli-responsive polymers: Biomedical applications and challenges for clinical translation. Adv Drug Deliv Rev 65(1): 10-16.

26. Zheng H, Xing L, Cao Y, Che S (2013) Coordination bonding based pHresponsive drug delivery systems. Coordin Chem Rev 257(11-12): 1933-1944.

27. Xing L, Zheng H, Cao Y, Che S (2012) Coordination Polymer Coated Mesoporous Silica Nanoparticles for pH-Responsive Drug Release. Adv Mater 24(48): 6433-6437.

28. Xing L, Cao Y, Che S (2012) Synthesis of core-shell coordination polymer nanoparticles (CPNs) for pH-responsive controlled drug release. Chem Commun (Camb) 48: 5995-5997. 


\section{Novel Approaches in Drug Designing \& Development}

29. Lowman A, Morishita M, Kajita M, Nagai T, Peppas NA (1999) Oral delivery of insulin using $\mathrm{pH}$-responsive complexation gels. J Pharm Sci 88(9): 933-937.

30. Gupta P, Vermani K, Garg S (2002) Hydrogels: from controlled release to $\mathrm{pH}-$ responsive drug delivery. Drug Discov Today 7(10): 569-579.

31. Koetting MC, Guido JF, Gupta M, Zhang A, Peppas NA (2016) pHResponsive and Enzymatically-Responsive Hydrogel Microparticles for the Oral Delivery of Therapeutic Proteins: Effects of Protein Size, Crosslinking Density, and Hydrogel Degradation on Protein Delivery J Control Release 221: 18-25.

32. Boussif O, Lezoualch F, Zanta MA, Mergny MD, Scherman D, et al. (1995) A versatile vector for gene and oligonucleotide transfer into cells in culture and in vivo: polyethylenimine. Proc Natl Acad Sci USA 92(16): 7297-7301.

33. Mi P, Kokuryo D, Cabral H, Wu H, Terada Y, et al. (2016) A pH-activatable nanoparticle with signal-amplification capabilities for non-invasive imaging of tumour malignancy. Nat Nanotechnol 11: 724-730.

34. Ling D, Park W, Park SJ, Lu Y, Kim KS (2014) Multifunctional Tumor pH-Sensitive Self-Assembled Nanoparticles for Bimodal Imaging and Treatment of Resistant Heterogeneous Tumors. J Am Chem Soc 136(15): 5647-5655.

35. Xing L, Zheng H, Che S (2011) A pH-Responsive Cleavage Route Based on a Metal-Organic Coordination Bond. Chemistry 17(26): 7271-7275.

36. Gao C, Zheng H, Xing L, Shu M, Che S (2010) Designable Coordination Bonding in Mesopores as a pH-Responsive Release System. Chem Mater 22(19): 5437-5444.

37. Zheng H, Gao C, Peng B, Shu M, Che S (2011) pH-Responsive Drug Delivery System Based on Coordination Bonding in a Mesostructured Surfactant/Silica Hybrid. J Phys Chem C 115(15): 7230-7237.

38. Zheng H, Wang Y, Che S (2011) Coordination Bonding-Based Mesoporous Silica for pH-Responsive Anticancer Drug Doxorubicin Delivery. J Phys Chem C 115(34): 16803-16813.

39. Rim HP, Min KH, Lee HJ, Jeong SY, Lee SC (2011) pH-Tunable Calcium Phosphate Covered Mesoporous Silica Nanocontainers for Intracellular Controlled Release of Guest Drugs. Angew Chem Int Ed 50(38): 88538857.

40. Lu Y, Hu Q Lin Y, Pacardo DB, Wang C, et al. (2015) Transformable liquid-metal nanomedicine. Nat Commun 6: 10066. doi:10.1038/ ncomms10066.

41. Zhang S, Bellinger AM, Glettig DL, Barman R, Lee YA, et al. (2015) A pHresponsive supramolecular polymer gel as an enteric elastomer for use in gastric devices. Nat Mater 14(10): 1065-1071.

42. Slaughter BV, Khurshid SS, Fisher OZ, Khademhosseini A, Peppas NA (2009) Hydrogels in Regenerative Medicine. Adv Mater 21(32-33) 3307-3329.

43. You JO, Rafat M, Almeda D, Maldonado N, Guo P, et al. (2015) pHresponsive scaffolds generate a pro-healing response. Biomaterials 57 22-32.

44. Wu G, Fang YZ, Yang S, Lupton JR, Turner ND (2004) Glutathione Metabolism and Its Implications for Health. J Nutr 134(3): 489-492.

45. Kuppusamy P, Li H, Ilangovan G, Cardounel AJ, Zweier JL, et al. (2002) Noninvasive Imaging of Tumor Redox Status and Its Modification by Tissue Glutathione Levels. Cancer Res 62(1): 307-312.

46. Meng F, Hennink WE, Zhong Z (2009) Reduction-sensitive polymers and bioconjugates for biomedical applications. Biomaterials 30(12) 2180-2198.

47. Zhao M, Biswas A, Hu B, Joo KI, Wang P, et al. (2011) Redox-responsive nanocapsules for intracellular protein delivery. Biomaterials 32(22): 5223-5230.
48. Miyata K, Kakizawa Y, Nishiyama N, Harada A, Yuichi Yamasaki, et al (2004) Block Catiomer Polyplexes with Regulated Densities of Charge and Disulfide Cross-Linking Directed To Enhance Gene Expression. J Am Chem Soc 126(8): 2355-2361.

49. Napoli A, Valentini M, Tirelli N, Muller M, Hubbell JA (2004) Oxidationresponsive polymeric vesicles. Nat Mater 3(3): 183-189.

50. Shim MS, Xia YA (2013) A Reactive Oxygen Species (ROS)-Responsive Polymer for Safe, Efficient, and Targeted Gene Delivery in Cancer Cells. Angew Chem Int Ed Eng 52(27): 6926-6929.

51. Ma Y, Dong WF, Hempenius MA, Mohwald H, Julius Vancso G (2006) Redox-controlled molecular permeability of composite-wall microcapsules. Nat Mater 5(9): 724-729.

52. Aran K, Parades J, Rafi M, Yau JF, Acharya AP, et al. (2015) StimuliResponsive Electrodes Detect Oxidative Stress and Liver Injury. Adv Mater 27(8): 1433-1436.

53. Buzea C, Pacheco, Robbie K (2007) Nanomaterials and nanoparticles: Sources and toxicity. Biointerphases 2(4): MR17-71.

54. De Jong WH, Borm PJ (2008) Drug delivery and nanoparticles: Applications and hazards. Int J Nanomedicine 3(2): 133-149.

55. Dobrovolskaia MA, McNeil SE (2007) Immunological properties of engineered nanomaterials. Nature Nanotechnology 2: 469-478.

56. Moghimi SM, Hunter AC, Murray JC (2005) Nanomedicine: current status and future prospects. FASEB J 19(3): 311-330.

57. Fadeel B, Garcia-BAE (2010) Better safe than sorry: Understanding the toxicological properties of inorganic nanoparticles manufactured for biomedical applications. Adv Drug Deliv Rev 62(3): 362-374.

58. Dobrovolskaia MA, McNeil SE (2007) Immunological properties of engineered nanomaterials. Nature Nanotechnology 2: 469-478.

59. Fischer HC, Chan WC (2007) Nanotoxicity: the growing need for in vivo study. Curr Opin Biotechnol 18(6): 565-571.

60. Tortora M, Cavalieri F, Mosesso P, Ciaffardini F, Melone F, et al. (2014) Ultrasound Driven Assembly of Lignin into Microcapsules for Storage and Delivery of Hydrophobic Molecules. Biomacromolecules 15(5): 1634-1643.

61. Bartzoka ED, Lange H, Thiel K, Crestini C (2016) Coordination Complexes and One-Step Assembly of Lignin for Versatile Nanocapsule Engineering. ACS Sustainable Chem Eng 4(10): 5194-5203.

62. Betard A, Fischer RA (2012) Metal-Organic Framework Thin Films: From Fundamentals to Applications. Chem Rev 112(2): 1055-1083.

63. Yan Y, Huang J (2010) Hierarchical assemblies of coordination supramolecules. Coord Chem Rev 254(9-10): 1072-1080.

64. Manickam S, Ashokkumar M (2014) Cavitation: A Novel EnergyEfficient Technique for the Generation of Nanomaterials. CRC Press, USA, ISBN 9789814411547 p. 554

65. Thakur VK, Thakur MK (2015) Handbook of Polymers for Pharmaceutical Technologies. Structure and Chemistry; John Wiley \& Sons, USA, ISBN: 978-1-119-04134-4

66. Whitesides GM, Kriebel JK, Mayers BT (2005) Self-Assembly and Nanostructured Materials. In: Huck WTS (Ed.), Nanoscale Assembly. Nanostructure Science and Technology Springer USA, pp. 217-239, ISBN: 978-0-387-23608-7.

67. Gleiter H (2000) Nanostructured materials: basic concepts and microstructure. Acta Mater48(1): 1-29.

68. Ahmad MZ, Akhter S, Jain GK, Rahman M, Pathan SA, et al. (2010) Metallic nanoparticles: technology overview \& drug delivery applications in oncology. Expert Opin Drug Deliv 7(8): 927-942.

69. Lai MK, Chang CY, Lien YW, Tsiang RC (2006) Application of gold 
nanoparticles to microencapsulation of thioridazine. J Control Release 111(3): 352-361.

(C) Commons Attribution 4.0 License

70. Dobrovolskaia MA, Germolec DR, Weaver JL (2009) Evaluation of nanoparticle immunotoxicity. Nature Nanotechnology 4: 411-414.

\section{Your next submission with Juniper Publishers will reach you the below assets}

- Quality Editorial service

- Swift Peer Review

- Reprints availability

- E-prints Service

- Manuscript Podcast for convenient understanding

- Global attainment for your research

- Manuscript accessibility in different formats

( Pdf, E-pub, Full Text, Audio)

- Unceasing customer service

Track the below URL for one-step submission https://juniperpublishers.com/online-submission.php 